\title{
Electron beam surface remelting of AISI D2 cold-worked die steel
}

\author{
R.G. Song ${ }^{\mathrm{a}, \mathrm{b}, *}$, K. Zhang ${ }^{\mathrm{a}}$, G.N. Chen ${ }^{\mathrm{a}}$ \\ ${ }^{\mathrm{a}}$ Laboratory for Surface Modification, Materials Center, Institute of Mechanics, Chinese Academy of Sciences, Beijing 100080, PR China \\ ' Institute for Computational Science and Engineering, Ocean University of Qingdao, Shandong 266003, PR China
}

Received 16 October 2001; accepted in revised form 11 March 2002

\begin{abstract}
Electron beam surface remelting has been carried out on AISI D2 cold-worked die steel. The microstructure and hardening behavior of the electron beam surface remelted AISI D2 cold-worked die steel have been studied by means of optical microscopy and Vickers hardness testing. It was found that AISI D2 steel can be successfully surface hardened by electron beam surface remelting. This surface hardening effect can be attributed to microstructural refinement following electron beam surface remelting. (C) 2002 Elsevier Science B.V. All rights reserved.
\end{abstract}

Keywords: Electron beam; Surface remelting; Microstructure; Hardening; AISI D2 cold-worked die steel

\section{Introduction}

AISI D2 steel is extensively used as cold-worked die due to its relatively good wear resistance. A significant problem in application is the tendency toward wear when subjected to large pressure, bending, shock and friction during its service. The reason for this failure is related to the relatively lower surface hardness. By modifying the surface, its properties may, however, be improved. Recently, electron and laser beams have been used as a method for surface remelting and alloying of materials [1-6]. In the electron beam surface remelting process, a surface layer is fused by means of electron beam and resolidified quickly. The rapid solidification yields improvement of microstructure and increases the hardness of the remelted layer. Comparing with the conventional surface processing, high energy beam surface modification has many advantages, such as saving energy resources, avoiding environmental pollution, raising labor efficiency, improving the quality of products,

\footnotetext{
*Corresponding author. Present address: Research Institute of Biological Resources, National Institute of Advanced Industrial Science and Technology (AIST), 2-17-2-1 Tsukisamu-Higashi, Toyohiraku, Sapporo 062-8517, Japan. Tel.: +81-11-857-8960; fax: + 81-11-857-8984.

E-mail address: song.rg@aist.go.jp (R.G. Song).
}

etc. Therefore, a lot of research work on the field mentioned above has already been carried out [7-14]. In the present research, AISI D2 cold-worked die steel was irradiated by electron beam, then the microstructure and hardening behavior of the surface layer after treatment was studied.

\section{Experimental details}

The material used in this study was as-quenched AISI D2 cold-worked die steel with the chemical composition as shown in Table 1.

Electron beam surface remelting was carried out on a $60-\mathrm{kW}$ moderate voltage electron beam welding machine made in Russia. The operation conditions were as follows: $60 \mathrm{kV}$ for accelerating voltage, $10 \mathrm{~mA}$ for beam current, $1.2 \mathrm{~m} / \mathrm{min}$ for scanning velocity.

Transverse and longitudinal sections of the electron beam traces were cut as specimens for metallographic examination by optical microscopy (OM). All the specimens were ground and polished. Etching was performed using a solution containing $5 \mathrm{ml} \mathrm{HNO}_{3}$ and $95 \mathrm{ml}$ ethanol. The microhardness depth profile of the electron beam treated specimen was measured using a Vickers hardness tester under a load of $0.1 \mathrm{~kg}$. 
Table 1

Chemical composition of AISI D2 steel (wt.\%)

\begin{tabular}{lllllllll}
\hline $\mathrm{C}$ & $\mathrm{Cr}$ & $\mathrm{Mo}$ & $\mathrm{V}$ & $\mathrm{Mn}$ & $\mathrm{Si}$ & $\mathrm{P}$ & $\mathrm{S}$ & $\mathrm{Fe}$ \\
\hline 1.60 & 12.0 & 0.55 & 0.15 & 0.40 & 0.40 & 0.030 & 0.030 & $\mathrm{Bal}$.
\end{tabular}

\section{Results and discussion}

\subsection{Microstructure evolution under electron beam sur- face remelting}

The starting microstructure of as-quenched AISI D2 steel consisted of martensite, carbides and residual austensite, as shown in Fig. 1. Moreover, the carbides were coarse and inhomogeneous.

Fig. 2 shows the transverse section of a single electron beam surface remelting track. Four distinct areas can be seen. The first one is more lightly etched and forms a melted layer on the surface of the material. The second one is a more darkly etched region and forms a very shallow phase transformation hardening layer below the surface. The third one is the most darkly etched region, which extends to greater depth below the surface and forms a transition layer. The second and third regions form a zone beneath the melted layer, which has clearly undergone a series of phase transformations and is called a 'heat affected zone' here (HAZ). Finally, the gray area at the bottom is the part of the material, which remained unaffected by the process. In addition, it can also be seen that the figuration of the surface layer after electron beam remelting is better than that of laser irradiation. Simultaneously, the tendency to form cracks is very low.

The microstructures of a single remelting track (longitudinal section) are shown in Fig. 3. Typical epitaxial growth can be clearly seen in the melted layer. The morphology of the solidified grains varies with their position in the melted pool, i.e. small equiaxed grains near the melted layer/substrate interface (Fig. 3a) $\rightarrow$

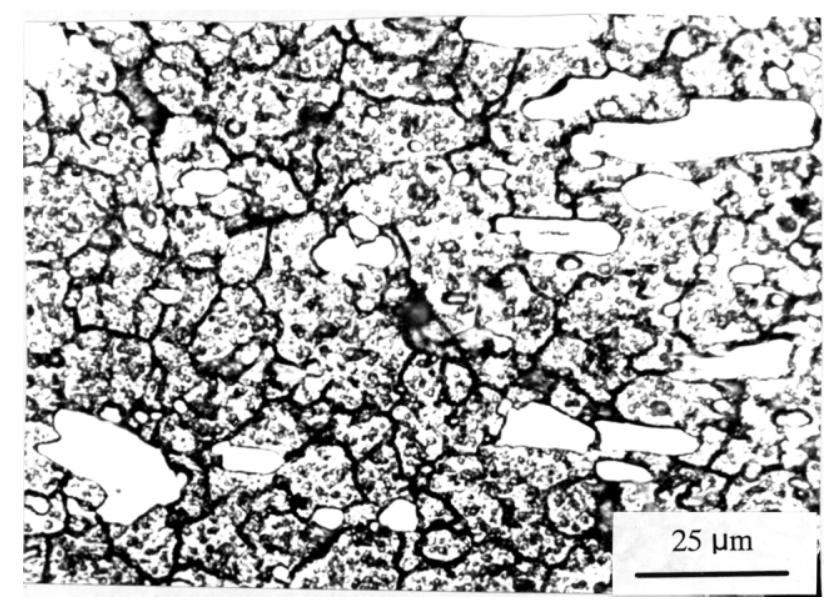

Fig. 1. Starting microstructure of AISI D2 steel.

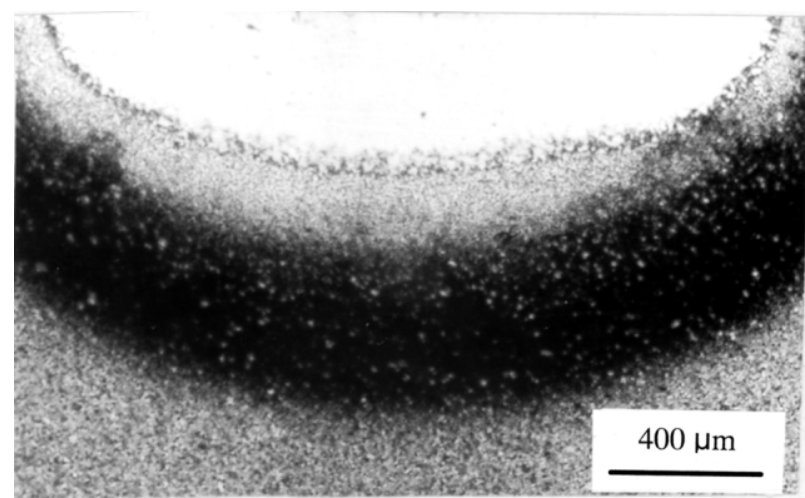

Fig. 2. Transverse section of electron beam surface remelting single track on AISI D2 steel.

cellular/dendritic structures at the center of the melted layer (Fig. 3b) $\rightarrow$ directional dendrites near the surface (Fig. 3c). According to the principles of solidification [15], the morphology of solidified material is controlled by the temperature gradient $(G)$ in the liquid near the advancing interface and by the growth rate $(R)$. With an increase in the ratio $G / R$, solidification morphology evolves from dendritic to cellular and to planar. In the present case, $G / R$ decreases due to recalescence and the low thermal conductivity of AISI D2 steel as the solidification proceeds from the pool bottom towards the pool surface; this may account for the solidification morphology observed following electron beam surface remelting. It should be pointed out that the usual planar crystal growth at the pool bottom did not occur in Fig. 3a, the reason perhaps being that $G$ at the start of solidification was not high enough to meet the planar crystal growth condition. Compared with that of the original material (see Fig. 1), the microstructure of the melted layer is greatly refined.

The microstructure of phase transformation hardening layer was found to consist of martensite, a dispersion of fine carbides and residual austensite, as shown in Fig. 4. This microstructure is an indication that the thermal cycle in this zone, in spite of the very rapid heating and small austenitizing times, fully austenitizes the phase transformation hardening region below the melted layer.

The microstructure of the most darkly etched region in Fig. 2 consists of tempered sorbite, in addition to martensite and carbides which were present in the starting microstructure (Fig. 5). It is evident that the thermal cycle was inadequate to austenitize this area, but was enough to cause a high temperature tempering transition.

\subsection{Hardening effects of electron beam surface remelting}

Fig. 6 shows the microhardness profile of AISI D2 cold-worked die steel obtained on the cross section through the center of single-track runs. It can be seen 

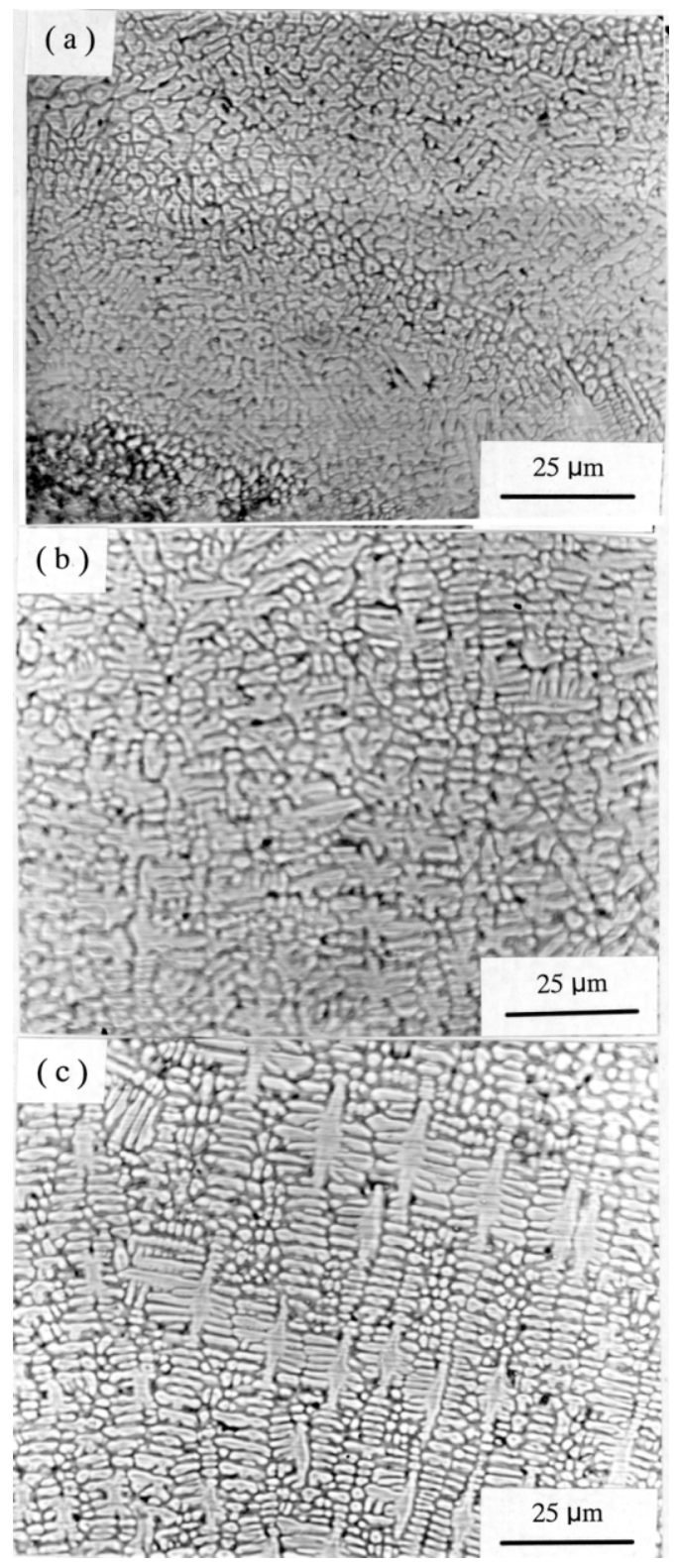

Fig. 3. Microstructure of the electron beam melt pool: (a) pool bottom; (b) pool center; and (c) pool surface.

that AISI D2 steel revealed a promising hardening response to electron beam surface remelting. The existence of three areas within the melted layer and HAZ of the irradiated specimen is reflected in the corresponding microhardness profile. The melted layer on the surface had a microhardness approaching $490 \mathrm{HV}_{0.1}$; while the shallow phase transformation hardening layer had maximum microhardness approaching $866 \mathrm{HV}_{0.1}$. Both areas above had a microhardness value higher than that of base metal. This can be attributed to the microstructural refinement following electron beam surface remelting. An abrupt decrease of the microhardness occurred within the high temperature tempering layer, which was slightly lower than the base metal. The

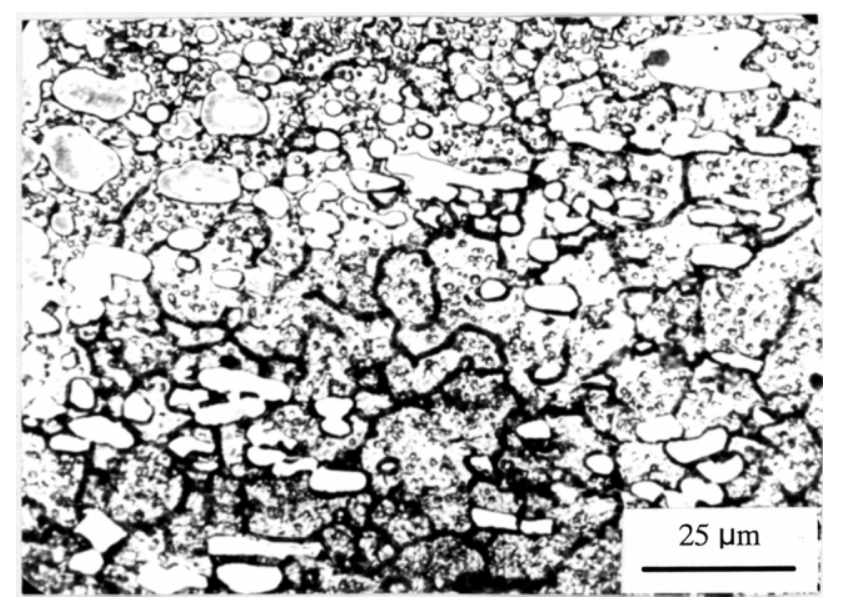

Fig. 4. Microstructure of phase transformation hardening layer.

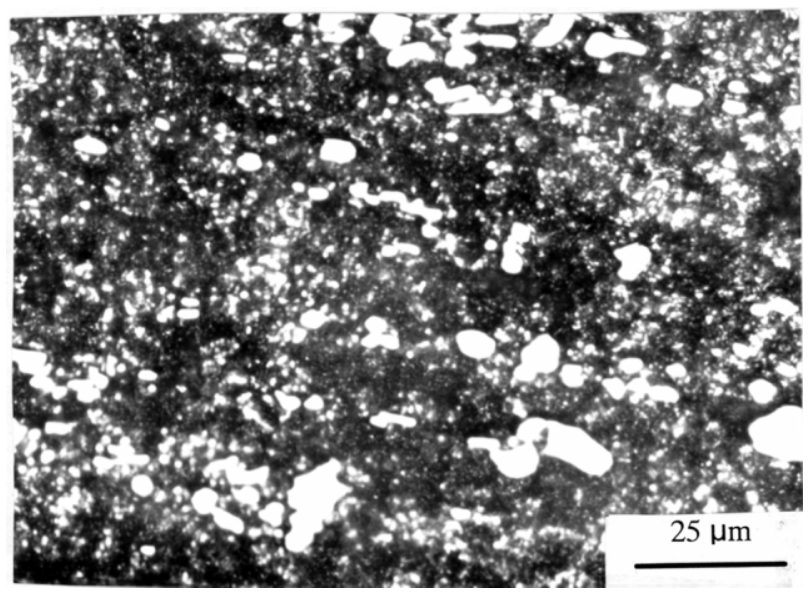

Fig. 5. Microstructure of transition layer.

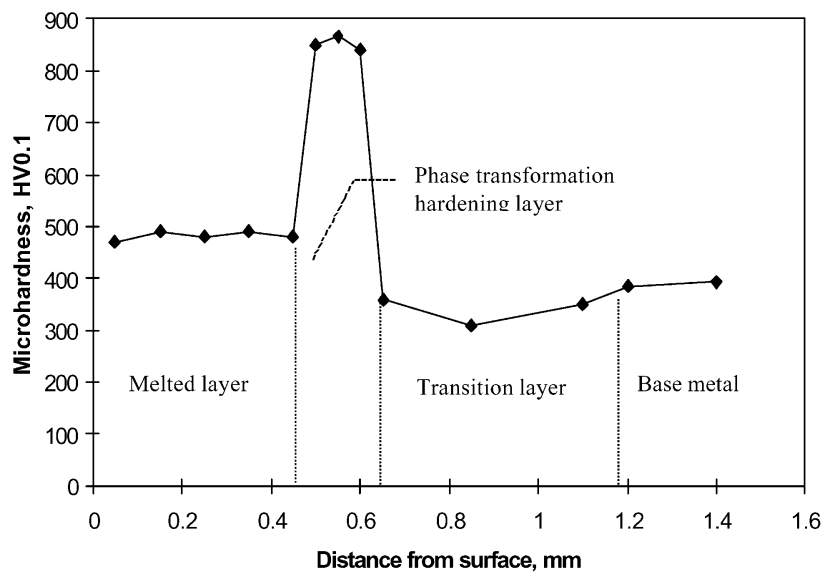

Fig. 6. Hardening response of AISI D2 steel to electron beam surface remelting.

reason is that the microstructure in this region mainly consisted of tempered sorbite. Finally, the base metal microhardness was unaltered at $380 \mathrm{HV}_{0.1}$. 


\section{Conclusions}

1. Electron beam surface remelting of AISI D2 coldworked die steel causes a significant hardening effect on the surface of the material. The microhardness of the phase transformation hardening layer increased by a factor of 2 times the initial (prior to electron beam treatment) microhardness of the material.

2. There are different solidification parameters for different positions in the melted layer. The microstructure at the melted layer bottom was typical epitaxial growth small equiaxed grains, whereas the microstructures at the middle and top were cellular/dendritic and dendritic crystal, respectively.

3. The microstructure of the phase transformation hardening layer consisted of martensite, a dispersion of fine carbides and residual austensite.

4. A high temperature tempering of the starting microstructure of AISI D2 steel took place inside the transition layer, resulting in the formation of tempered sorbite, accompanied by an abrupt decrease of microhardness.

\section{Acknowledgments}

The financial aid of the National Natural Science Foundation of China under grant No. 59836220 is gratefully acknowledged.

\section{References}

[1] A. Tauqir, H. Zaigham, F.H. Hashmi, A.Q. Khan, J. Mater. Sci. 32 (1997) 465-468.

[2] S.H. Choo, S. Lee, S.J. Kwon, Metall. Mater. Trans. 30A (1999) 1211-1221.

[3] G. Mueller, G. Schumacher, D. Straub, Surf. Coat. Technol. 108-109 (1998) 43-47.

[4] R.G. Song, W.Z. He, W.D. Huang, Surf. Coat. Technol. 130 (2000) 20-23.

[5] Q.Y. Pan, W.D. Huang, R.G. Song, Y.H. Zhou, G.L. Zhang, Surf. Coat. Technol. 102 (1998) 245-255.

[6] T.M. Yue, J.K. Yu, H.C. Man, Surf. Coat. Technol. 137 (2001) 65-71.

[7] P. Petrov, Vacuum 48 (1997) 49-50.

[8] K. Zhang, G.N. Chen, Mater. Sci. Eng. 292A (2000) 229-331.

[9] L.W. Tsay, Z.W. Lin, R.K. Shiue, C. Chen, Mater. Sci. Eng. 290A (2000) 46-54.

[10] J.R. Hwang, C.P. Fung, Surf. Coat. Technol. 80 (1996) 271-278.

[11] A.B. Markov, V.P. Rotshtein, Nucl. Instr. Meth. Phys. Res. B 132 (1997) 79-86.

[12] D.I. Proskurovsky, V.P. Rotshtein, G.E. Ozur, Y.F. Ivanov, A.B. Markov, Surf. Coat. Technol. 125 (2000) 49-56.

[13] A.B. Markov, Y.F. Ivanov, D.I. Proskurovsky, V.P. Rotshtein, Mater. Manuf. Process. 14 (1999) 205-216.

[14] D. Dimitrov, M. Aprakova, S. Valkanov, P. Petrov, Vacuum. 49 (1998) 239-246.

[15] M.C. Flemings, Solidification Processing, McGraw-Hill, New York and London, 1974. 